\title{
The Study on Safety Awareness of Sports in University Students
}

\author{
Younshin Nam* \\ Duksung Women's University
}

\author{
Article Info \\ Received 2021.12.01. \\ Revised 2021.12.16. \\ Accepted 2021.12.23. \\ Correspondence* \\ Younshin Nam \\ younshinkr@duksung.ac.kr
}

Key Words

University Students,

Sports,

Safety awareness,

Survey

본 연구는 2020년 덕성여대 연구비 지원 으로 이루어졌음.
PURPOSE This study was to examine safety awareness of sports among university students. METHODS Total 1950 university students of 9 regions responded to questionnaires on safety awareness of sports with using simple random sampling. The date were analyzed by frequency analysis and Two-way ANOVA. RESULTS The results of this study werew as follows: Fistly, male students were experienced safety awareness education more than female students. In addition, the education of safety awareness of sports took place in sports field, but most of students did not aware of safety personnel. Secondly, university students thought that sports was not safe because sports facilities and equipments were not managed and they were worn out. Thirdly, they perceived sports safety was managed generally normal. Furthermore, they perceived the aging of facilities and equipments at sports sites was major factor in the occurrence of safety accidents. In order to reduce sports safety accidents, it is necessary to facilitate safety education of sports at government. CONCLUSIONS The results of this study will be used as fundamental information to raise safety awareness in university students and to establish safe sports culture.

\section{서론}

안전은 사건 및 사고와 재난 등을 사전에 예방하고 지키며, 사고가 발생했을 경우 신속하게 대처하는 것을 말한다(Lee, 2015). 사고의 위험과 안전의 관계는 네 단계로 나누어 이해할 수 있는데, 첫 번째 가 위험단계(risk)다. 위험단계는 가능성의 의미를 가지고 있는 위 기가 존재하며, 두 번째 단계인 위기단계(crisis)는 위험요인이 현 실화되어 인지된 혼란의 상황이 야기될 수 있고, 세 번째 단계인 재 난단계(disaster)는 결과론적 함의를 가진 것으로 그 결말이 부정 적인 위기이며, 네 번째 단계인 안전단계(safety)는 위험이 발생하 거나 사고가 날 염려가 없거나 혹은 그런 상태를 의미한다(Jung \& Yoon, 2009). 안전에 대한 올바른 의식 상태는 안전을 유지하고 증진시키기 위해 어떠한 행동을 해야 하는 것이 중요하고 바람직하 다(Kim et al., 2019). 결론적으로 안전의식은 안전에 대한 관심, 구체적 행동 그리고 실천하는 정도를 말한다. 이는 교육이나 훈련 을 통해 후천적으로 학습되어 질 수 있다. 개인이나 공동체가 안전 하려면 교육이나 훈련을 통해 안전문화가 확산되는 것이 필요하다.

(cc) This is an open-access article distributed under the terms of the Creative Commons Attribution Non-Commercial License (http://creativecommons.org/ licenses/by-nc/4.0/), which permits unrestricted non-commercial use, distribution, and reproduction in any medium, provided the original work is properly cited.
안전문화는 사고 발생 시 원인과 방법을 이해함으로써 사고 예방에 가장 적절하고 적합한 방법을 개발할 수 있고, 그 원인을 밝힘으로 서 유사사고 발생을 미연에 방지하는 역할을 한다(Lee, 2015).

사람들은 행복한 삶의 추구에 관심이 많고, 행복한 삶은 적극적인 스포츠 활동 참여와 깊은 관계가 깊다(Park, 2009). 그러나 스포츠 참여가 확대 될수록 스포츠 안전사고도 지속적으로 발생하고 있다 (Lee et al., 2019). 스포츠 안전이라 함은 스포츠 활동 시 어떤 사 고나 재난 등을 사전에 예방하는 것이라 할 수 있다. 그러나 사고와 재난은 시기와 정도에 있어 불확실성을 가지고 있어 이에 대비하 는 것이 쉽지 않다. 스포츠 안전사고의 원인은 이용자 개인의 부주 의, 법제도의 미흡, 시설 및 프로그램 관리의 부실, 지도자-행사운 영자 · 행사참여자에 대한 안전교육의 부재 등 복합적 요인의 혼재 로 보고 있다(Hong et al., 2018). 스포츠 안전사고를 포함하여 모 든 안전사고에 대해 많은 사람들은 불가항력적이며 우발적인 것으 로 여기기 쉬우나 결코 우발적으로 발생하는 것이 아니고 불안전한 행위와 조건이 선행된다(Yoon et. al., 2014). 발생된 스포츠 안전 사고는 스포츠 활동을 위축시키는 요인이 되기도 한다. 국민생활체 육조사(2020)에 의하면 운동 중 상해로 인한 진료 일수는 평균 6.1 일이나 되었고, 운동 중 상해를 경험한 경우, 체육활동 참여수준이 감소했다고 응답한 사람도 $21.3 \%$ 였다. 대부분의 안전사고는 부주 의, 안전 불감증으로 인한 관리소홀 및 안일한 태도에서 발생하기 
때문에 안전한 사회 환경을 조성하는 것이 필요하다. 안전한 사회 환경을 만들기 위해 안전교육이 필수적이라 할 수 있는데 안전교육 이란, 안전한 생활을 할 수 있도록 필요한 지식을 주고 태도나 행동 을 바람직한 방향으로 바꾸어 나가는 것이다(Chung \& Oh, 2016). 다양한 스포츠 안전사고로부터 건강하고 안전한 스포츠 활동환경 을 조성하기 위해서는 안전교육을 통산 지식, 기능, 태도를 습관화 할 시킬 필요가 있다.

대학생들은 학교에서 전공이나 교양 수업을 통해 스포츠 활동에 접 할 기회가 많아 그들은 다른 연령층보다 스포츠 안전사고에 노출되 는 확률이 높다. 발생할 수 있는 스포츠 안전사고는 사전에 스포츠 안 전에 대한 지식을 습득시켜 줌으로써 스포츠 안전사고가 발생할 수 있는 불안전한 조건을 배제할 수 있다. 스포츠 안전의식은 모든 스포 츠 사고와 위험의 가능성을 없애거나 예방하는데 필요한 지식과 기 능을 습득하는 것으로서(Lee, 2010), 스포츠 안전의식 함양은 자신의 안전수준이 어느 정도인지 인지하고 있는 것에서부터 시작된다고 할 수 있다. 알고 있는 스포츠 안전에 대한 지식을 안전 행동으로 이어질 수 있도록 습관화하는 것이 중요하다.

2019년 행정안전부조사에 의하면 일반국민의 사회 전반 안전 체감 도는 5점 만점의 기준에서 2.65점을 나타나 높은 점수라 인정하기 어 렵다. 개인이 안전을 얼마나 중시하는지에 대한 인식은 비교적 높지 만(3.62점), 우리 사회가 안전을 중요시하는 지 여부는 상대적으로 낮 았다(2.99점). 안전 체감도가 낮은 것은 국민들의 안전의식이 낮은 것 에 원인이라고 여겨진다. 안전의식은 일상생활에서의 위험으로부터 안전을 유지하고 사고를 예방하기 위해 가지는 안전에 대한 인지도를 의미한다(Kim, 2015).

스포츠 분야에 있어서 스포츠 안전사고에 대한 정확한 통계자료가 없어 스포츠 안전사고 분석에 어려움이 있으나, 전국의 대학생을 대 상으로 스포츠 안전의식을 조사하면 스포츠 안전의식을 높이기 위해 필요한 법적, 제도적 근거를 마련하는데 기초자료로 활용될 수 있을 것으로 사료된다.

이에 본 연구는 대학생을 대상으로 스포츠 안전의식의 정도를 알아 보기 위하여 안전교육 정도, 스포츠 안전의식, 안전관리 현황을 조사 하고자 한다.

\section{연구방법}

\section{연구대상}

대학생의 스포츠 안전의식을 조사하기 위하여 전국을 7 개 권역(서 울, 경기, 충청, 강원, 전라, 경상, 제주)의 대학을 모집단으로 설정 하고 단순무선표집법(simple random sampling)을 이용하여 연구 대상 대학으로 선정하였다. 7 개 권역의 대학 336 개 중 난수표를 이 용하여 총 38개 대학을 선정하였다. 지역을 안배하여 대학을 선정 하였으나 지역별로 응답자 수는 차이가 있었다. 지역별 연구대상자 의 분포를 살펴보면, 서울지역 493명(25.3\%), 경기 357명(18.3\%), 충청 328명(16.8\%), 강원 78명(4.0\%), 전라 508명(26.1\%), 경상 131 명(6.7\%), 제주 55명(2.8\%)이었다. 설문은 2021년 9월 1일부 터 10 월 15 일까지 표집 하였다. 설문문항을 시작하기 전 설문의 내 용과 목적을 설명하는 글을 제시하고, 설문 진행 동의를 묻는 질문 을 선행 한 후 온라인으로 설문을 실시하였다. 설문에 응답한 연구
대상은 총 1950명이었다. 남성 963명(49.4\%), 여성 987(50.6\%) 이었으며, 학년 별로 살펴보면 1학년 579명(29.7\%), 2학년 528명 (27.1\%), 3학년 450명(23.1\%), 4학년 393명(20.2\%)로 3, 4학년 보다는 1,2 학년 학생이 다소 많았다. 전공별로 살펴보면 체육계열 1218 명(62.5\%), 비 체육계열 732명(37.5\%)로 체육계열이 많았다. 연구 대상의 일반적 특성은 〈Table 1 〉과 같다.

\section{연구도구}

본 연구의 목적을 달성하기 위해 설문지를 조사도구로 사용하였 다. 선정된 문항들과 변인들은 선행연구를 통해 구성한 후 대학교 수 2 인, 과학원 박사 1 인, 스포츠안전 전문가 1 인에게 설문지 내용 의 검토를 부탁하여 내용타당도(content validity)를 확보하였다. 설문 문항은 인구통계학적 특성 5 문항, 안전교육 4문항, 스포츠 안 전의식 2 문항, 스포츠 안전관리 6 문항으로 구성되었다. 설문구성은 〈Table 2〉와 같다.

\section{자료처리방법}

본 연구의 목적을 달성하기 위하여 SPSS 23.0을 이용하여 분석을 실시하였다. 본 연구에 참여한 대상자의 인구통계학적 특성을 확인 하기 위하여 빈도분석(frequency analysis)을 사용하였고, 수집된 자료의 기술통계 분석을 실시하였다. 집단 간 평균 차이를 검증하 기 위해 일원변량분산분석(one-way ANAOVA)을 사용하였다. 일 원변량분산분석의 사후 검증은 Turkey방법으로 분석하였다. 통계 적 유의 수준은 $\alpha=.05$ 로 설정하였다.

Table 1. Demographic characteristics of participants

\begin{tabular}{|c|c|c|c|}
\hline Variables & Level & Number & Percent \\
\hline \multirow{2}{*}{ Sex } & Male & 963 & 49.4 \\
\hline & Female & 987 & 50.6 \\
\hline \multirow{4}{*}{ Grade } & Freshman & 579 & 29.7 \\
\hline & Sophomore & 528 & 27.1 \\
\hline & Junior & 450 & 23.1 \\
\hline & Senior & 383 & 20.2 \\
\hline \multirow{7}{*}{ Residence area } & Seoul & 493 & 25.3 \\
\hline & Gyonggi & 357 & 18.3 \\
\hline & Chungcheong & 328 & 16.8 \\
\hline & Kangwon & 78 & 4.0 \\
\hline & Chonna & 508 & 26.1 \\
\hline & Gyeongsang & 131 & 6.7 \\
\hline & Jeju & 55 & 2.8 \\
\hline \multirow{2}{*}{ Major } & $\begin{array}{l}\text { Physical } \\
\text { education }\end{array}$ & 1218 & 62.5 \\
\hline & $\begin{array}{l}\text { Non-physical } \\
\text { education }\end{array}$ & 732 & 37.5 \\
\hline \multirow{2}{*}{$\begin{array}{l}\text { Accident } \\
\text { experience }\end{array}$} & Yes & 1066 & 54.7 \\
\hline & No & 884 & 45.3 \\
\hline
\end{tabular}




\section{연구결과}

스포츠는 그 특성상 안전사고의 위험이 내제되어 있다. 자연의 환경 속에서 여러 스피드와 스릴, 그리고 묘기를 즐기는 종목이 많아 안전 사고의 위험은 더욱 노출된다. 우리의 건강하고 행복한 삶을 추구하 기 위해 즐기는 여가활동이 사고가 발생하여 심각한 상해를 입거나 생명을 잃는다면 매우 불행한 일이 될 것이다(Shon, 2011). 스포츠 를 제대로 즐기기 위해서는 무엇보다도 스포츠 안전이 중요하고 상 해를 예방하기 위해서는 무엇보다도 안전교육이 필요하다. 또한, 구 조적으로 안전하게 스포츠 활동을 할 수 있는 시설안전이 확보되어 야 한다(Kim et al., 2019). 이와 같은 선행연구를 토대로 본 연구 설문에서 스포츠 안전교육과 스포츠 안전관리 항목을 선정하였다. 안전의식은 안전에 대한 분위기가 생성되어 있으면 안전에 대한 행 동을 적극적으로 행하게 되어(Shin \& Kim, 2021) 안전의식 문항 또 한 추가하여 본 연구 설문을 구성하였다. 이에 본 연구 설문은 스포 츠 안전교육, 안전의식, 안전관리로 구분하여 진행하였다.

\section{스포츠 안전교육}

'스포츠 안전에 대한 교육을 받은 적이 있느냐'의 질문에 남성은 여성보다 안전교육을 받은 경험이 다소 많았고, 남성과 여성 모두 안전교육을 받은 경험이 있는 사람이 없는 사람보다 많았다. 남성 과 여성 간 차이가 있는 것으로 나타났다 $(t=-4.604, p=.000)$. 학년 간에는 차이가 없었으며 $(F=.490, p=.484), 2$ 학년 학생이 다소 다 른 학년 학생보다 안전교육을 많이 받은 것으로 조사되었다. 체육 을 전공으로 한 학생이 비 체육계열 학생보다 안전교육을 더 받은 것으로 나타났다 $(t=-7.501, p=.000)$. 안전사고 유무에 따른 스포츠 안전교육 경험에 대한 차이는 유의한 차이가 있는 것으로 조사되어 스포츠 안전사고의 경험이 있는 사람이 스포츠 활동 시 안전교육을 더 받는 것으로 조사되었다( $t=-7.968, p=.000)$. 결과는 〈Table 3〉 과 같다.

안전 교육을 받은 경험이 없는 사람 중 기회가 있다면 스포츠 안 전교육 참여를 희망하는지 묻는 질문은 남성과 여성의 차이가 없었 으나 $(t=-.454, p=.650)$, 남성과 여성 모두 기회가 주어진다면 안전 교육에 참여하겠다는 사람이 참여하지 않겠다는 사람보다 많았다. 학년별에도 차이는 없었다 $(t=1.483, p=.218)$.

그러나 체육계열 학생과 비 체육계열 학생 간에는 차이가 있었 다 $(t=-5.874, p=.000)$. 이는 체육계열 학생이 비 체육계열 학생보 다 스포츠 안전교육에 대해 참여의사가 있는 것으로 여겨진다. 안 전사고 유무에 따라서는 차이가 없었다 $(t=-1.069, p=.286)$. 결과는 〈Table 4〉와 같다.

〈Table 5〉에서 보는 바와 같이 학교에서 안전교육을 받은 장소를 묻는 질문에 남성과 여성 모두 스포츠 현장보다는 학교에서 안전교 육을 받은 것으로 나타났으며, 여성이 남성보다 학교에서 안전교육 을 더 많았다 $(t=2.996, p=.000)$. 학년별 차이는 없었다 $(t=1.483$, $p=.218)$. 전공별로는 차이가 있었다 $(t=6.600, p=.000)$. 체육계열 학생보다 비 체육계열 학생은 학교에서 안전교육을 많이 받는 것 으로 조사되었다. 사고 유무에 따라서는 차이가 있었다 $(t=3.684$, $p=.000)$. 사고 경험이 없는 사람이 학교에서 안전교육을 더 많이 받은 것으로 미루어 보아 안전사고 예방을 위해서도 학교에서 안전 교육은 필수적으로 이루어져야 한다.
Table 2. Summary of the scales used

\begin{tabular}{ccc}
\hline Scale & \multicolumn{1}{c}{ Items } & Number of questions \\
\hline Demographics & $\begin{array}{c}\text { Sex, Grade, Residence } \\
\text { area, Major, Accident } \\
\text { experience }\end{array}$ & 5 \\
Safety & $\begin{array}{l}\text { Safety education } \\
\text { experience, Safety } \\
\text { education participation, } \\
\text { Education }\end{array}$ & 4 \\
& $\begin{array}{c}\text { Safety education place, } \\
\text { Safety officer, }\end{array}$ \\
\hline Safety & $\begin{array}{c}\text { Safety thought, Reason } \\
\text { for un safety }\end{array}$ \\
\hline Safety & $\begin{array}{c}\text { Pre-safety management, } \\
\text { Countermeasures, } \\
\text { Corrective action, } \\
\text { Management } \\
\text { Safety judgment criteria, } \\
\text { Cause of accident, } \\
\text { Government alternative }\end{array}$ \\
\hline
\end{tabular}

Table 3. Safety training education experience

\begin{tabular}{|c|c|c|c|c|c|c|c|}
\hline \multirow{2}{*}{ Variables } & \multirow{2}{*}{ Contents } & \multicolumn{2}{|c|}{ Frequency } & \multicolumn{2}{|c|}{ Percentage } & \multirow{2}{*}{$t / \mathrm{F}$} & \multirow{2}{*}{$\begin{array}{c}p / \\
\text { Post- } \\
\text { hoc }\end{array}$} \\
\hline & & Yes & No & Yes & No & & \\
\hline \multirow{2}{*}{ Sex } & $\mathrm{M}$ & 750 & 213 & 77.9 & 22.1 & \multirow{2}{*}{-4.604} & \multirow{2}{*}{$.000 * *$} \\
\hline & $\mathrm{F}$ & 678 & 309 & 68.7 & 31.3 & & \\
\hline \multirow{4}{*}{ Grade } & $1 \mathrm{st}$ & 416 & 163 & 71.8 & 28.2 & \multirow{4}{*}{.490} & \multirow{4}{*}{.484} \\
\hline & 2nd & 405 & 123 & 76.7 & 23.3 & & \\
\hline & $3 \mathrm{rd}$ & 332 & 118 & 73.8 & 26.2 & & \\
\hline & 4th & 275 & 118 & 70.0 & 30.0 & & \\
\hline \multirow{2}{*}{ Major } & $\mathrm{PE}$ & 962 & 256 & 79.0 & 21.0 & \multirow{2}{*}{-7.501} & \multirow{2}{*}{$.000 * *$} \\
\hline & Non-PE & 466 & 266 & 63.7 & 36.3 & & \\
\hline \multirow{2}{*}{$\begin{array}{l}\text { Accident } \\
\text { experience }\end{array}$} & Yes & 857 & 209 & 80.4 & 19.6 & \multirow{2}{*}{-7.968} & \multirow{2}{*}{$.000 * *$} \\
\hline & No & 571 & 313 & 64.6 & 35.4 & & \\
\hline
\end{tabular}

$* p<.05, * * p<.01$

Table 4. Safety education participation

\begin{tabular}{|c|c|c|c|c|c|c|c|}
\hline \multirow{2}{*}{ Variables } & \multirow{2}{*}{ Contents } & \multicolumn{2}{|c|}{ Frequency } & \multicolumn{2}{|c|}{ Percentage } & \multirow{2}{*}{$t / \mathrm{F}$} & \multirow{2}{*}{$\begin{array}{c}p / \\
\text { Post- } \\
\text { hoc }\end{array}$} \\
\hline & & Yes & No & Yes & No & & \\
\hline \multirow{2}{*}{ Sex } & $\mathrm{M}$ & 129 & 84 & 60.6 & 39.4 & \multirow{2}{*}{-.454} & \multirow{2}{*}{.650} \\
\hline & $\mathrm{F}$ & 181 & 128 & 58.6 & 41.4 & & \\
\hline \multirow{4}{*}{ Grade } & $1 \mathrm{st}$ & 101 & 62 & 62.0 & 38.0 & \multirow{4}{*}{1.483} & \multirow{4}{*}{.218} \\
\hline & 2nd & 69 & 54 & 56.1 & 43.9 & & \\
\hline & $3 \mathrm{rd}$ & 63 & 33 & 53.4 & 46.6 & & \\
\hline & 4th & 77 & 41 & 65.3 & 34.7 & & \\
\hline \multirow{2}{*}{ Major } & PE & 184 & 72 & 71.9 & 28.1 & \multirow{2}{*}{-5.874} & \multirow{2}{*}{$.000 * *$} \\
\hline & Non-PE & 126 & 140 & 47.4 & 52.6 & & \\
\hline \multirow{2}{*}{$\begin{array}{l}\text { Accident } \\
\text { experience }\end{array}$} & Yes & 130 & 79 & 62.2 & 37.8 & \multirow{2}{*}{-1.069} & \multirow{2}{*}{.286} \\
\hline & No & 180 & 133 & 57.5 & 42.5 & & \\
\hline
\end{tabular}


스포츠 현장에 안전담당자가 배치되어 있는 지 묻는 질문에 남 성과 여성의 차이가 있었다( $t=-2.648, p=.008)$. 스포츠 현장에 안 전담당자가 있는지 모른다고 응답한 사람도 많아 스포츠 현장에서 안전담당자의 위치나 존재를 알려 사고가 발생했을 때 빠른 대처가 이루어지도록 해야 할 것이다. 학년 별로 차이가 있었다 $(F=9.085$, $p=.000)$. 1 학년 학생은 2학년과 3학년, 4 학년과 차이가 있었으며, 3 학년은 4 학년과 차이가 있었다. 전공별로도 차이가 있었다 $(t=-$ $3.365, p=.001)$. 체육계열 학생은 비 체육계열 학생보다 스포츠 현 장에서 안전담당자가 배치되어 있다고 인지하고 있었다. 사고 유무 에 따라서는 차이가 없었다 $(t=-1.784, p=.075)$ (Table 6).

\section{스포츠 안전의식}

스포츠 안전의식 중 '스포츠가 안전하다고 생각하는가?' 의 질문에 남성과 여성의 차이는 없었으며( $t=.091, p=.928)$. 남성과 여성 모 두 스포츠가 안전하다고 생각하기 보다는 안전하지 않다고 생각하 는 사람이 많았다. 학년별로 살펴보면, 2 학년 학생은 1 학년, 3 학년, 4 학년 학생과 차이가 있었다 $F=2.694, p=.045)$. 전공별 차이는 없 었다 $(t=.582, p=.561)$. 그러나 사고의 경험 유무에 따라 차이가 있 는 것으로 조사되었다 $(t=3.013, p=.003)$ (Table 7).

스포츠가 안전하지 않다고 생각하는 이유는 무엇인가 묻는 질문

Table 5. Safety education place

\begin{tabular}{|c|c|c|c|c|c|c|c|}
\hline \multirow{2}{*}{ Variables } & \multirow{2}{*}{ Contents } & \multicolumn{2}{|c|}{ Frequency } & \multicolumn{2}{|c|}{ Percentage } & \multirow{2}{*}{$t / \mathrm{F}$} & \multirow{2}{*}{$\begin{array}{c}p / \\
\text { Post-hoc }\end{array}$} \\
\hline & & School & Field & School & Field & & \\
\hline \multirow{2}{*}{ Sex } & $\mathrm{M}$ & 488 & 262 & 65.1 & 34.9 & \multirow{2}{*}{2.996} & \multirow{2}{*}{$.003 * *$} \\
\hline & $\mathrm{F}$ & 491 & 187 & 72.4 & 27.6 & & \\
\hline \multirow{4}{*}{ Grade } & $1 \mathrm{st}$ & 322 & 94 & 77.4 & 22.6 & \multirow{4}{*}{1.483} & \multirow{4}{*}{.218} \\
\hline & 2 nd & 266 & 139 & 65.7 & 34.3 & & \\
\hline & $3 r d$ & 227 & 105 & 68.4 & 31.6 & & \\
\hline & 4 th & 164 & 111 & 59.6 & 40.4 & & \\
\hline \multirow{2}{*}{ Major } & $\mathrm{PE}$ & 606 & 356 & 63.0 & 37.0 & \multirow{2}{*}{6.600} & \multirow{2}{*}{$.000 * *$} \\
\hline & Non-PE & 373 & 93 & 80.0 & 20.0 & & \\
\hline \multirow{2}{*}{ Accident experience } & Yes & 556 & 301 & 64.9 & 35.1 & \multirow{2}{*}{3.684} & \multirow{2}{*}{$.000 * *$} \\
\hline & No & 423 & 148 & 74.1 & 25.9 & & \\
\hline
\end{tabular}

$* p<.05, * * p<.01$

Table 6. Safety officer

\begin{tabular}{|c|c|c|c|c|c|c|c|c|c|}
\hline \multirow{2}{*}{ Variables } & \multirow{2}{*}{ Contents } & \multicolumn{3}{|c|}{ Frequency } & \multicolumn{3}{|c|}{ Percentage } & \multirow{2}{*}{$t / \mathrm{F}$} & \multirow{2}{*}{$\begin{array}{c}p / \\
\text { Post-hoc }\end{array}$} \\
\hline & & Yes & No & Don't know & Yes & No & Don't know & & \\
\hline \multirow{2}{*}{ Sex } & M & 368 & 152 & 230 & 49.1 & 20.3 & 30.7 & \multirow{2}{*}{-2.648} & \multirow{2}{*}{$.008 * *$} \\
\hline & $\mathrm{F}$ & 315 & 88 & 276 & 46.4 & 13.0 & 40.6 & & \\
\hline \multirow{4}{*}{ Grade } & $1 \mathrm{st}$ & 189 & 53 & 174 & 45.4 & 12.7 & 41.8 & \multirow{4}{*}{9.085} & \multirow{4}{*}{$\begin{array}{c}.000 * * \\
{[1],[2,3],[2,4}\end{array}$} \\
\hline & 2nd & 203 & 70 & 132 & 50.1 & 17.3 & 32.6 & & \\
\hline & $3 \mathrm{rd}$ & 149 & 57 & 126 & 44.9 & 17.2 & 38.0 & & \\
\hline & 4 th & 142 & 60 & 74 & 51.4 & 21.7 & 26.8 & & \\
\hline \multirow{2}{*}{ Major } & $\mathrm{PE}$ & 484 & 168 & 311 & 50.3 & 17.4 & 32.3 & \multirow{2}{*}{-3.365} & \multirow{2}{*}{$.001 * *$} \\
\hline & Non-PE & 199 & 72 & 195 & 42.7 & 15.5 & 41.8 & & \\
\hline \multirow{2}{*}{$\begin{array}{c}\text { Accident } \\
\text { experience }\end{array}$} & Yes & 406 & 181 & 270 & 47.4 & 21.1 & 31.5 & \multirow{2}{*}{-1.784} & \multirow{2}{*}{.075} \\
\hline & No & 277 & 59 & 236 & 48.4 & 10.3 & 41.3 & & \\
\hline
\end{tabular}

$* p<.05, * * p<.01$, post-hoc [ ] 
에 1순위, 2순위 모두 남 - 여 간 차이가 없었다(1순위: $t=-1.899$, $p=.059,2$ 순위: $t=.339, p=.735$ ). 1 순위에 있어 남성은 '시설 및 장 비가 관리되지 않거나 노후가 되어서'라고 응답한 사람이 제일 많 았고(44.3\%), 여성은 '안전사고 관련 뉴스 및 기사를 봤기 때문'이 라고 응답한 사람이 가장 많았다(43\%). 2순위에서는 여성도 '시설 및 장비가 관리되지 않거나 노후하기 때문'이라고 응답한 사람이 가장 많은 것으로 조사되어(40.0\%), 안전의식을 높이기 위해서 시 설관리가 우선시 되어야 한다.

1순위, 2순위 모두 학년 별 차이는 없었다(1순위: $F=1.629$, $p=.184,2$ 순위: $F=1.113, p=.345$ ). 전공에 따라서 1순위는 체육계 열 학생과 비 체육계열 학생 간 차이가 있었으나 2순위에는 차이가 없었다(1순위: $t=-2.274, p=.024,2$ 순위: $t=.626, p=.532$ ). 체육계 열 학생 중 1 순위는 '시설 및 장비가 관리되지 않거나 노후하기 때
문'이라고 응답한 학생이 가장 많았고(40.1\%), 비 체육계열 학생은 '안전사고 관련 뉴스 및 기사를 봤기 때문'이라고 응답한 학생이 많 았다(55.9\%).

사고 경험 유무에 따라서는 차이가 없었다. (1순위: $t=-.923$, $p=.357,2$ 순위: $t=-.155, p=.877$ ). 그 결과는 〈Table 8〉과 같다.

\section{스포츠 안전관리}

스포츠 안전관리 정도를 알아보기 위하여 5점 척도를 사용하여 설 문을 실시하였다. 가장 먼저 '안전사고 예방/방지를 위한 사전 관리 를 잘하고 있다' 의 질문에 남성과 여성 간 차이가 있었다 $(t=4.220$, $p=.000)$. 학년간 살펴보면 차이가 있었다( $F=4.717, p=.003)$. 4 학 년 학생은 2 학년과 3 학년 학생과 차이가 있었다. 전공별로 살펴보

Table 7. Idea that sports are safe

\begin{tabular}{|c|c|c|c|c|c|c|c|c|c|c|c|c|c|}
\hline \multirow{2}{*}{ Variables } & \multirow{2}{*}{ Contents } & \multicolumn{5}{|c|}{ Frequency } & \multicolumn{5}{|c|}{ Percentage } & \multirow{2}{*}{$t / \mathrm{F}$} & \multirow{2}{*}{$\begin{array}{c}p / \\
\text { Post-hoc }\end{array}$} \\
\hline & & Never & No safe & Average & Safe & Very & Never & No safe & Average & Safe & Very & & \\
\hline \multirow{2}{*}{ Sex } & $\mathrm{M}$ & 58 & 305 & 280 & 94 & 12 & 7.7 & 40.7 & 37.4 & 12.6 & 1.5 & \multirow{2}{*}{0.91} & \multirow{2}{*}{.928} \\
\hline & $\mathrm{F}$ & 21 & 342 & 215 & 93 & 7 & 3.1 & 50.4 & 31.7 & 13.7 & 1.01 & & \\
\hline \multirow{4}{*}{ Grade } & $1 \mathrm{st}$ & 26 & 188 & 144 & 50 & 8 & 6.2 & 46.9 & 36.3 & 10.1 & 0.5 & \multirow{4}{*}{2.694} & \multirow{4}{*}{$\begin{array}{c}.045^{*} \\
{[2],[1,3,4]}\end{array}$} \\
\hline & $2 n d$ & 25 & 190 & 147 & 41 & 2 & 6.2 & 46.9 & 36.3 & 10.1 & 0.5 & & \\
\hline & $3 r d$ & 19 & 146 & 116 & 47 & 4 & 5.7 & 44.0 & 34.9 & 14.2 & 1.2 & & \\
\hline & 4 th & 9 & 123 & 88 & 49 & 5 & 3.3 & 44.9 & 32.1 & 17.9 & 1.8 & & \\
\hline \multirow{2}{*}{ Major } & $\mathrm{PE}$ & 64 & 417 & 333 & 131 & 16 & 6.7 & 43.4 & 34.7 & 13.6 & 1.7 & \multirow{2}{*}{.582} & \multirow{2}{*}{.561} \\
\hline & Non-PE & 15 & 230 & 162 & 56 & 3 & 3.2 & 49.4 & 34.8 & 12.0 & 0.6 & & \\
\hline \multirow{2}{*}{$\begin{array}{l}\text { Accident } \\
\text { experience }\end{array}$} & Yes & 35 & 395 & 280 & 131 & 16 & 4.1 & 46.1 & 32.7 & 15.3 & 1.9 & \multirow{2}{*}{3.013} & \multirow{2}{*}{$.003 *$} \\
\hline & No & 44 & 252 & 215 & 56 & 3 & 7.7 & 44.2 & 37.7 & 9.8 & 1.3 & & \\
\hline
\end{tabular}

$* p<.05, * * p<.01$, post-hoc [ ]

Table 8. Reasons for sports insecurity (1st rank(2rank))

\begin{tabular}{|c|c|c|c|c|c|c|c|c|c|c|c|}
\hline \multirow[b]{2}{*}{ Variables } & \multirow[b]{2}{*}{ Contents } & \multicolumn{4}{|c|}{ Frequency } & \multicolumn{4}{|c|}{ Percentage } & \multirow[b]{2}{*}{$t / \mathrm{F}$} & \multirow[b]{2}{*}{$\begin{array}{c}p / \\
\text { Post-hoc }\end{array}$} \\
\hline & & $\begin{array}{c}\text { Old } \\
\text { facility }\end{array}$ & $\begin{array}{c}\text { Accident } \\
\text { news }\end{array}$ & $\begin{array}{l}\text { Negative } \\
\text { review }\end{array}$ & $\begin{array}{c}\text { Lack of } \\
\text { safety } \\
\text { education }\end{array}$ & $\begin{array}{c}\text { Old } \\
\text { facility }\end{array}$ & $\begin{array}{l}\text { Accident } \\
\text { news }\end{array}$ & $\begin{array}{c}\text { Negative } \\
\text { review }\end{array}$ & $\begin{array}{c}\text { Lack of } \\
\text { safety } \\
\text { education }\end{array}$ & & \\
\hline \multirow{2}{*}{ Sex } & M & $47(39)$ & $27(31)$ & $5(27)$ & $27(31)$ & $44.3(36.8)$ & $25.5(29.2)$ & $4.7(8.5)$ & $25.5(29.2)$ & \multirow{2}{*}{$\begin{array}{r}-1.899 \\
(.339)\end{array}$} & \multirow{2}{*}{$\begin{array}{c}.059 \\
(.735)\end{array}$} \\
\hline & $\mathrm{F}$ & $32(40)$ & $43(25)$ & $2(8)$ & $23(27)$ & $32.0(40.0)$ & $43.0(25.0)$ & $2.0(8.0)$ & $23.0(27.0)$ & & \\
\hline \multirow{4}{*}{ Grade } & $1 \mathrm{st}$ & $20(22)$ & $26(15)$ & $3(15)$ & $9(5)$ & $34.5(37.9)$ & $44.8(25.9)$ & $5.2(25.9)$ & $15.5(8.6)$ & \multirow{4}{*}{$\begin{array}{c}1.629 \\
(1.113)\end{array}$} & \multirow{4}{*}{$\begin{array}{l}.184 \\
(.345)\end{array}$} \\
\hline & 2 nd & $20(9)$ & $13(16)$ & $0(4)$ & $10(14)$ & $46.5(20.9)$ & $30.2(37.2)$ & $0.0(9.3)$ & $23.3(32.6)$ & & \\
\hline & $3 r d$ & $22(21)$ & 14(10) & $1(3)$ & $14(17)$ & $43.1(41.2)$ & $27.5(19.6)$ & $2.0(5.5)$ & $27.5(5.9)$ & & \\
\hline & 4 th & $17(27)$ & $17(11)$ & $3(5)$ & $17(11)$ & $31.5(50.0)$ & $31.5(20.3)$ & $5.5(9.2)$ & $31.5(20.3)$ & & \\
\hline \multirow{2}{*}{ Major } & $\mathrm{PE}$ & $59(56)$ & $33(42)$ & $16(33)$ & $42(16)$ & $40.1(38.1)$ & $22.4(28.6)$ & $10.9(22.4)$ & $28.6(10.9)$ & \multirow{2}{*}{$\begin{array}{r}-2.274 \\
(.626)\end{array}$} & \multirow{2}{*}{$\begin{array}{l}.024 * \\
(.532)\end{array}$} \\
\hline & Non-PE & $20(23)$ & $33(16)$ & 1(19) & $5(16)$ & $33.9(39.0)$ & $55.9(27.1)$ & $1.8(32.2)$ & $9.2(10.9)$ & & \\
\hline \multirow{2}{*}{$\begin{array}{l}\text { Accident } \\
\text { experience }\end{array}$} & Yes & $57(58)$ & $41(42)$ & $43(32)$ & $6(15)$ & $38.8(39.5)$ & $27.9(28.6)$ & $29.3(21.8)$ & $4.1(10.2)$ & \multirow{2}{*}{$\begin{array}{c}-.923 \\
(-.155)\end{array}$} & \multirow{2}{*}{$\begin{array}{c}.357 \\
(.877)\end{array}$} \\
\hline & No & $22(21)$ & $9(16)$ & $27(20)$ & $1(2)$ & $37.3(35.6)$ & $15.3(27.1)$ & $45.8(33.9)$ & $1.7(8.3)$ & & \\
\hline
\end{tabular}

$* p<.05, * * p<.01$ 
면 체육계열 학생과 비 체육계열 학생 간 차이가 있었다 $(t=5.273$, $p=.000)$. 체육계열 학생은 비 체육계열 학생보다 안전사고 예방 및 방지를 위한 사전관리를 잘 하고 있었다. 사고경험 유무에 따라서는 집단 간 차이가 없었다( $t=-.250, p=.802)$. 결과는 〈Table 9〉과 같다.

안전사고 시 대응조치에 대한 질문에 남성과 여성 간의 차이가 있었다 $(t=5.734, p=.000)$. 남성이 여성보다 사고가 발생하였을 때 대응조치를 더 잘하고 있는 것으로 조사되었다. 그러나 학년별로 는 차이가 없었다 $(F=2.512, p=.057)$. 전공별로 살펴보면, 체육계 열 학생들이 사고에 잘 대응조치를 하고 있는 것으로 조사되었다 $(t=5.530, p=.000)$. 비 체육계열 학생들을 위하여 안전사고가 발생 하였을 때 어떻게 대응해야 하는지 교육과 함께 대응매뉴얼이 필요 하다고 사료된다. 사고 경험 유무에 따라 차이가 없었다 $(t=1.893$, $p=.059)$ (Table 10).
사고가 발생하였을 때 책임소재 규명, 보상 등 수습조치를 잘 하 고 있는지를 묻는 질문에 남성과 여성의 차이가 있었다 $(t=2.818$, $p=.005)$. '잘 모른다'는 여성의 비율이 남성보다 높았다.

학년별 차이가 있었으며( $F=4.286, p=.005), 2$ 학년과 4 학년 학생 간 차이가 있었다. 전공별에도 차이가 있었다 $(t=3.594, p=.000)$. 체 육계열 학생이 비 체육계열 학생보다 사고가 발생하였을 때 책임소재 나 규명, 보험 등 수습조치를 잘하고 있는 것으로 나타났다. 사고 경 험 유무에 따라서는 차이가 없었다( $t=-1.226, p=.220)$ (Table 11).

Table 9. Safety accident pre-management

\begin{tabular}{|c|c|c|c|c|c|c|c|c|c|c|c|c|c|}
\hline \multirow[b]{2}{*}{ Variables } & \multirow[b]{2}{*}{ Contents } & \multicolumn{5}{|c|}{ Frequency } & \multicolumn{5}{|c|}{ Percentage } & \multirow[b]{2}{*}{$t / \mathrm{F}$} & \multirow{2}{*}{$\begin{array}{c}p / \\
\text { Post-hoc }\end{array}$} \\
\hline & & Never & No & Average & Little & $\begin{array}{l}\text { Very } \\
\text { well }\end{array}$ & Never & No & Average & Little & $\begin{array}{l}\text { Very } \\
\text { well }\end{array}$ & & \\
\hline \multirow{2}{*}{ Sex } & M & 13 & 49 & 290 & 396 & 215 & 1.3 & 5.1 & 30.1 & 41.1 & 22.3 & \multirow{2}{*}{4.220} & \multirow{2}{*}{$.000 * *$} \\
\hline & $\mathrm{F}$ & 13 & 90 & 334 & 385 & 165 & 1.3 & 9.1 & 33.8 & 39.0 & 16.7 & & \\
\hline \multirow{4}{*}{ Grade } & $1 \mathrm{st}$ & 6 & 39 & 198 & 228 & 108 & 1.0 & 6.7 & 34.2 & 39.4 & 18.7 & \multirow{4}{*}{4.717} & \multirow{4}{*}{$\begin{array}{c}.003^{*} \\
{[4 \mathrm{th}, 1 \mathrm{st}]} \\
{[1 \mathrm{st}, 3 \mathrm{rd},} \\
2 \mathrm{nd}]\end{array}$} \\
\hline & 2nd & 5 & 31 & 158 & 214 & 120 & 0.9 & 5.9 & 29.9 & 40.5 & 22.7 & & \\
\hline & $3 \mathrm{rd}$ & 4 & 33 & 141 & 179 & 93 & 0.9 & 7.3 & 31.3 & 39.8 & 20.7 & & \\
\hline & 4th & 11 & 36 & 127 & 160 & 59 & 2.8 & 9.2 & 32.3 & 40.7 & 15.0 & & \\
\hline \multirow{2}{*}{ Major } & PE & 9 & 72 & 364 & 511 & 262 & 0.7 & 5.9 & 29.9 & 42.0 & 21.5 & \multirow{2}{*}{5.273} & \multirow{2}{*}{$.000 * *$} \\
\hline & Non-PE & 17 & 67 & 260 & 270 & 118 & 2.3 & 9.2 & 35.5 & 36.9 & 16.1 & & \\
\hline \multirow{2}{*}{$\begin{array}{l}\text { Accident } \\
\text { experience }\end{array}$} & Yes & 14 & 73 & 339 & 446 & 194 & 1.3 & 6.8 & 31.8 & 41.8 & 18.2 & \multirow{2}{*}{-.250} & \multirow{2}{*}{.802} \\
\hline & No & 12 & 66 & 285 & 335 & 186 & 1.4 & 7.5 & 32.2 & 37.9 & 21.0 & & \\
\hline
\end{tabular}

$* p<.05, * * p<.01$, post-hoc [ ]

Table 10. Response in case of safety accidents

\begin{tabular}{|c|c|c|c|c|c|c|c|c|c|c|c|c|c|}
\hline \multirow[b]{2}{*}{ Variables } & \multirow[b]{2}{*}{ Contents } & \multicolumn{5}{|c|}{ Frequency } & \multicolumn{5}{|c|}{ Percentage } & \multirow[b]{2}{*}{$t / \mathrm{F}$} & \multirow[b]{2}{*}{$\begin{array}{c}p / \\
\text { Post-hoc }\end{array}$} \\
\hline & & Never & No & Average & Little & $\begin{array}{l}\text { Very } \\
\text { well }\end{array}$ & Never & No & Average & Little & $\begin{array}{l}\text { Very } \\
\text { well }\end{array}$ & & \\
\hline \multirow{2}{*}{ Sex } & M & 6 & 31 & 288 & 399 & 239 & 0.6 & 3.2 & 29.9 & 41.4 & 24.8 & \multirow{2}{*}{5.734} & \multirow{2}{*}{$.000 * *$} \\
\hline & $\mathrm{F}$ & 4 & 81 & 344 & 392 & 166 & 0.4 & 8.2 & 34.9 & 39.7 & 16.8 & & \\
\hline \multirow{4}{*}{ Grade } & $1 \mathrm{st}$ & 1 & 31 & 205 & 229 & 113 & 0.2 & 5.4 & 35.4 & 39.6 & 19.5 & \multirow{4}{*}{2.512} & \multirow{4}{*}{.057} \\
\hline & 2nd & 3 & 22 & 161 & 219 & 123 & 0.6 & 4.2 & 30.5 & 41.5 & 23.3 & & \\
\hline & $3 \mathrm{rd}$ & 3 & 22 & 152 & 174 & 99 & 0.7 & 4.9 & 33.8 & 38.7 & 22.0 & & \\
\hline & 4 th & 3 & 37 & 114 & 169 & 70 & 0.8 & 9.4 & 29.0 & 43.0 & 17.8 & & \\
\hline \multirow{2}{*}{ Major } & $\mathrm{PE}$ & 5 & 55 & 362 & 508 & 288 & 0.4 & 4.5 & 29.7 & 41.7 & 23.6 & \multirow{2}{*}{5.530} & \multirow{2}{*}{$.000 * *$} \\
\hline & Non-PE & 5 & 57 & 270 & 283 & 117 & 0.7 & 7.8 & 36.9 & 38.7 & 16.0 & & \\
\hline \multirow{2}{*}{$\begin{array}{c}\text { Accident } \\
\text { experience }\end{array}$} & Yes & 6 & 52 & 322 & 469 & 217 & 0.6 & 4.9 & 30.2 & 44.0 & 20.4 & \multirow{2}{*}{1.893} & \multirow{2}{*}{.059} \\
\hline & No & 4 & 60 & 310 & 322 & 188 & 0.5 & 6.8 & 35.1 & 36.4 & 21.3 & & \\
\hline
\end{tabular}

$* p<.05, * * p<.01$ 
Table 11. Safety accident management

\begin{tabular}{|c|c|c|c|c|c|c|c|c|c|c|c|c|c|}
\hline \multirow[b]{2}{*}{ Variables } & \multirow[b]{2}{*}{ Contents } & \multicolumn{5}{|c|}{ Frequency } & \multicolumn{5}{|c|}{ Percentage } & \multirow[b]{2}{*}{$t / \mathrm{F}$} & \multirow{2}{*}{$\begin{array}{c}p / \\
\text { Post-hoc }\end{array}$} \\
\hline & & Never & No & Average & Little & $\begin{array}{l}\text { Very } \\
\text { well }\end{array}$ & Never & No & Average & Little & $\begin{array}{l}\text { Very } \\
\text { well }\end{array}$ & & \\
\hline \multirow{2}{*}{ Sex } & M & 32 & 140 & 353 & 268 & 170 & 3.3 & 14.5 & 36.7 & 27.8 & 17.7 & \multirow{2}{*}{2.818} & \multirow{2}{*}{$.005^{* *}$} \\
\hline & $\mathrm{F}$ & 27 & 184 & 386 & 257 & 133 & 2.7 & 18.6 & 39.1 & 26.0 & 13.5 & & \\
\hline \multirow{4}{*}{ Grade } & $1 \mathrm{st}$ & 18 & 97 & 230 & 147 & 87 & 3.1 & 16.8 & 39.7 & 25.4 & 15.0 & \multirow{4}{*}{4.286} & \multirow{4}{*}{$\begin{array}{c}.005 * * \\
{[4 \mathrm{th}, 1 \mathrm{st},} \\
3 \mathrm{rd}],[1 \mathrm{st}, \\
3 \mathrm{rd}, 2 \mathrm{nd}]\end{array}$} \\
\hline & $2 \mathrm{nd}$ & 8 & 77 & 194 & 154 & 95 & 1.5 & 14.6 & 36.7 & 29.2 & 18.0 & & \\
\hline & $3 \mathrm{rd}$ & 13 & 76 & 174 & 116 & 71 & 2.9 & 16.9 & 38.7 & 25.8 & 15.8 & & \\
\hline & 4 th & 20 & 74 & 141 & 108 & 50 & 5.1 & 18.8 & 35.9 & 27.5 & 12.7 & & \\
\hline \multirow{2}{*}{ Major } & $\mathrm{PE}$ & 31 & 182 & 459 & 339 & 207 & 2.5 & 14.9 & 37.7 & 27.8 & 17.0 & \multirow{2}{*}{3.594} & \multirow{2}{*}{$.000 * *$} \\
\hline & Non-PE & 28 & 142 & 280 & 186 & 96 & 3.8 & 19.4 & 38.3 & 25.4 & 13.1 & & \\
\hline \multirow{2}{*}{$\begin{array}{c}\text { Accident } \\
\text { experience }\end{array}$} & Yes & 34 & 184 & 399 & 297 & 152 & 3.2 & 17.3 & 37.4 & 27.9 & 14.3 & \multirow{2}{*}{-1.226} & \multirow{2}{*}{.220} \\
\hline & No & 59 & 324 & 739 & 525 & 303 & 3.0 & 16.6 & 37.9 & 26.9 & 15.5 & & \\
\hline
\end{tabular}

$* p<.05, * * p<.01$, post-hoc [ ]

Table 12. Safety Criteria (1st rank(2rank))

\begin{tabular}{|c|c|c|c|c|c|c|c|c|c|c|c|c|c|}
\hline \multirow[b]{2}{*}{ Variables } & \multirow[b]{2}{*}{ Contents } & \multicolumn{5}{|c|}{ Frequency } & \multicolumn{5}{|c|}{ Percentage } & \multirow[b]{2}{*}{$t / \mathrm{F}$} & \multirow{2}{*}{$\begin{array}{c}p / \\
\text { Post- } \\
\text { hoc }\end{array}$} \\
\hline & & $\begin{array}{l}\text { Accident } \\
\text { occurred }\end{array}$ & $\begin{array}{c}\text { Evaluation } \\
\text { of people }\end{array}$ & $\begin{array}{c}\text { Safety } \\
\text { education }\end{array}$ & $\begin{array}{l}\text { Company } \\
\text { awareness }\end{array}$ & $\begin{array}{l}\text { Facility, } \\
\text { equipment } \\
\text { aging }\end{array}$ & $\begin{array}{l}\text { Accident } \\
\text { occurred }\end{array}$ & $\begin{array}{c}\text { Evaluation } \\
\text { of people }\end{array}$ & $\begin{array}{c}\text { Safety } \\
\text { education }\end{array}$ & $\begin{array}{l}\text { Company } \\
\text { awareness }\end{array}$ & $\begin{array}{l}\text { Facility, } \\
\text { equipment } \\
\text { aging }\end{array}$ & & \\
\hline \multirow{2}{*}{ Sex } & M & $\begin{array}{c}141 \\
(218)\end{array}$ & $\begin{array}{c}261 \\
(248)\end{array}$ & $\begin{array}{c}430 \\
(203)\end{array}$ & $\begin{array}{c}45 \\
(72)\end{array}$ & $\begin{array}{c}77 \\
(209)\end{array}$ & $\begin{array}{c}14.6 \\
(22.6)\end{array}$ & $\begin{array}{c}27.1 \\
(25.8)\end{array}$ & $\begin{array}{c}44.7 \\
(21.1)\end{array}$ & $\begin{array}{c}4.7 \\
(7.5)\end{array}$ & $\begin{array}{c}8.0 \\
(21.7)\end{array}$ & \multirow{2}{*}{$\begin{array}{c}3.245 \\
(3.216)\end{array}$} & \multirow{2}{*}{$\begin{array}{c}.001 * * \\
(.001 * *)\end{array}$} \\
\hline & $\mathrm{F}$ & $\begin{array}{c}202 \\
(271)\end{array}$ & $\begin{array}{c}238 \\
(253)\end{array}$ & $\begin{array}{c}444 \\
(212)\end{array}$ & $\begin{array}{c}51 \\
(87)\end{array}$ & $\begin{array}{c}46 \\
(152)\end{array}$ & $\begin{array}{c}20.5 \\
(27.5)\end{array}$ & $\begin{array}{c}24.1 \\
(25.6)\end{array}$ & $\begin{array}{c}45.0 \\
(21.5)\end{array}$ & $\begin{array}{c}5.2 \\
(8.8)\end{array}$ & $\begin{array}{c}4.7 \\
(15.4)\end{array}$ & & \\
\hline \multirow{4}{*}{ Grade } & $1 \mathrm{st}$ & $\begin{array}{c}95 \\
(141)\end{array}$ & $\begin{array}{c}145 \\
(152)\end{array}$ & $\begin{array}{c}276 \\
(127)\end{array}$ & $\begin{array}{c}21 \\
(36)\end{array}$ & $\begin{array}{c}40 \\
(119)\end{array}$ & $\begin{array}{c}16.4 \\
(24.4)\end{array}$ & $\begin{array}{c}25.0 \\
(26.3)\end{array}$ & $\begin{array}{c}47.7 \\
(21.9)\end{array}$ & $\begin{array}{c}3.6 \\
(6.2)\end{array}$ & $\begin{array}{c}6.9 \\
(20.6)\end{array}$ & \multirow{4}{*}{$\begin{array}{c}.717 \\
(5.182)\end{array}$} & \multirow{4}{*}{$\begin{array}{c}.542 \\
\left(.001^{* *}\right) \\
([3 \mathrm{rd}, \\
4 \mathrm{th}, 1 \mathrm{st}] \\
{[1 \mathrm{st},} \\
2 \mathrm{nd}])\end{array}$} \\
\hline & 2 nd & $\begin{array}{c}107 \\
(107)\end{array}$ & $\begin{array}{c}142 \\
(129)\end{array}$ & $\begin{array}{c}210 \\
(121)\end{array}$ & $\begin{array}{c}30 \\
(50)\end{array}$ & $\begin{array}{c}32 \\
(112)\end{array}$ & $\begin{array}{c}20.3 \\
(20.3)\end{array}$ & $\begin{array}{c}26.9 \\
(24.4)\end{array}$ & $\begin{array}{c}39.8 \\
(22.9)\end{array}$ & $\begin{array}{c}5.7 \\
(9.5)\end{array}$ & $\begin{array}{c}6.1 \\
(21.2)\end{array}$ & & \\
\hline & $3 \mathrm{rd}$ & $\begin{array}{c}70 \\
(135)\end{array}$ & $\begin{array}{c}111 \\
(115)\end{array}$ & $\begin{array}{l}214 \\
(82)\end{array}$ & $\begin{array}{c}22 \\
(43)\end{array}$ & $\begin{array}{c}32 \\
(70)\end{array}$ & $\begin{array}{c}15.6 \\
(30.0)\end{array}$ & $\begin{array}{c}24.7 \\
(25.6)\end{array}$ & $\begin{array}{c}47.6 \\
(18.2)\end{array}$ & $\begin{array}{c}4.9 \\
(9.6)\end{array}$ & $\begin{array}{c}7.1 \\
(15.6)\end{array}$ & & \\
\hline & 4 th & $\begin{array}{c}71 \\
(106)\end{array}$ & $\begin{array}{l}101 \\
(105)\end{array}$ & $\begin{array}{l}174 \\
(85)\end{array}$ & $\begin{array}{c}23 \\
(30)\end{array}$ & $\begin{array}{c}19 \\
(60)\end{array}$ & $\begin{array}{c}18.1 \\
(27.0)\end{array}$ & $\begin{array}{c}25.7 \\
(26.7)\end{array}$ & $\begin{array}{c}44.3 \\
(21.6)\end{array}$ & $\begin{array}{c}5.9 \\
(7.6)\end{array}$ & $\begin{array}{c}4.8 \\
(15.3)\end{array}$ & & \\
\hline \multirow[t]{2}{*}{ Major } & $\mathrm{PE}$ & $\begin{array}{c}189 \\
(281)\end{array}$ & $\begin{array}{c}352 \\
(330)\end{array}$ & $\begin{array}{c}521 \\
(267)\end{array}$ & $\begin{array}{c}59 \\
(97)\end{array}$ & $\begin{array}{c}85 \\
(223)\end{array}$ & $\begin{array}{c}15.5 \\
(23.1)\end{array}$ & $\begin{array}{c}28.9 \\
(27.1)\end{array}$ & $\begin{array}{l}42.8 \\
(21.9)\end{array}$ & $\begin{array}{c}4.8 \\
(8.0)\end{array}$ & $\begin{array}{c}7.0 \\
(18.3)\end{array}$ & \multirow{2}{*}{$\begin{array}{r}1.450 \\
-(1.208)\end{array}$} & \multirow{2}{*}{$\begin{array}{c}.147 \\
(.227)\end{array}$} \\
\hline & Non-PE & 208 & 171 & 148 & 62 & 138 & 28.4 & 23.4 & 20.2 & 8.5 & 18.9 & & \\
\hline \multirow{2}{*}{$\begin{array}{l}\text { Accident } \\
\text { experience }\end{array}$} & Yes & $\begin{array}{c}177 \\
(269)\end{array}$ & $\begin{array}{c}269 \\
(259)\end{array}$ & $\begin{array}{c}486 \\
(227)\end{array}$ & $\begin{array}{c}59 \\
(96)\end{array}$ & $\begin{array}{c}67 \\
(203)\end{array}$ & $\begin{array}{c}16.6 \\
(25.2)\end{array}$ & $\begin{array}{c}25.2 \\
(24.3)\end{array}$ & $\begin{array}{c}45.6 \\
(21.3)\end{array}$ & $\begin{array}{c}5.5 \\
(9.0)\end{array}$ & $\begin{array}{c}6.3 \\
(19.0)\end{array}$ & \multirow{2}{*}{$\begin{array}{l}1.276 \\
(.839)\end{array}$} & \multirow{2}{*}{$\begin{array}{c}.202 \\
(.401)\end{array}$} \\
\hline & No & $\begin{array}{c}166 \\
(220)\end{array}$ & $\begin{array}{l}230 \\
(242)\end{array}$ & $\begin{array}{c}388 \\
(188)\end{array}$ & $\begin{array}{c}37 \\
(63)\end{array}$ & $\begin{array}{c}56 \\
(158)\end{array}$ & $\begin{array}{c}18.8 \\
(24.9)\end{array}$ & $\begin{array}{c}26.0 \\
(27.4)\end{array}$ & $\begin{array}{c}43.9 \\
(21.3)\end{array}$ & $\begin{array}{c}4.2 \\
(9.0)\end{array}$ & $\begin{array}{c}6.3 \\
(17.9)\end{array}$ & & \\
\hline
\end{tabular}

$* p<.05, * * p<.01$, post-hoc [ ] 
'스포츠가 안전하다고 판단하는 기준이 무엇인가?'의 질문에 여 성과 남성 간 1 순위, 2 순위 모두 차이가 있었다(1순위: $t=3.245$, $p=.001,2$ 순위: $t=3.216, p=.001)$. 그러나 여성과 남성 모두 1순위에 있어서 안전교육 실시 여부가 스포츠 안전의 판단 기준은 안전교육 실시 여부였다. 2순위에 있어서 남성은 '주변사람들의 평가'가 안전 판단의 기준으로 우선 시 되었으며, 여성은 '안전사고 발생여부'가 우 선이었다.

스포츠가 안전하다고 판단하는 기준 2순위에 있어서 학년 별 차이 가 있었다(1순위: $F=.717, p=.542,2$ 순위: $F=5.182, p=.001)$. 2순위의 차이는 2 학년과 3 학년의 차이가 있는 것으로 나타났다. 1 순위에 있어 서는 모든 학년에서 안전교육 실시 여부가 가장 중요한 스포츠 안전 기준이었다. 2순위에서는 3학년과 4학년은 안전사고 발생 여부가 스 포츠 안전 판단 기준으로 중요하다고 생각하고 있었다.

전공별로 1,2 순위 모두 스포츠 안전 판단 기준에 차이가 없었다(1 순위: $t=1.450, p=.202,2$ 순위: $t=1.208, p=.227$ ). 체육계열 학생은 1 순위에 있어서 '안전교육 실시 여부'가 중요한 안전 판단 기준이었 고, 2순위에 있어서는 '주변사람들의 평가'가 기준이 되었다. 사고 경 험 유무에 따라서는 1순위, 2순위 모두 집단 간 차이가 없었다(1순 위:t=1.276, $p=.202,2$ 순위: $t=.839, p=.401) .1$ 순위에서는 사고 경험 과 상관없이 안전의 판단기준으로 안전교육 실시 여부를 들었다. 안 전교육이 스포츠 안전 판단기준이 될 수 있다는 점에 있어 학교에서 뿐 아니라 스포츠 현장에서도 안전교육 실시가 필요하다. 2순위로는 사고경험이 있는 집단에서는 '안전사고 발생 여부'가 중요한 기준이 되어 사고의 학습효과라 여겨진다(Table 12).

안전사고의 주된 이유가 무엇인지 묻는 질문에 남성과 여성의 차 이가 없었다( $t=1.499, p=.134)$. 남성과 여성 모두 안전사고 발생의 주된 원인은 시설 및 장비의 노후화로 생각하고 있었다. 학년별로 살 펴보면, 1 학년은 2학년, 3학년, 4학년과 차이가 있었다 $F=2.848$, $p=.036)$. 전공별 차이가 없었고( $t=1.069, p=2.85)$, 체육계열 학생과 비 체육계열 학생 모두 시설 및 장비의 노후화가 안전사고의 원인으 로 여기고 있었다. 사고 경험 유무에 따라서는 집단 간 차이가 있었다 $(t=4.505, p=.000)$. 사고의 경험이 없는 집단에서는 장비 및 시설의 노후화와 함께 이용자의 안전의식 부족 및 부주의를 들었다.

모든 집단에서 스포츠 안전사고가 발생하는 주된 이유로 시설 및 장비의 노후화를 들었다. 안전사고를 예방하기 위해서 시설이나 장비 의 정기적인 점검이 필요하다.(Table 13).

Table 13. Cause of accident

\begin{tabular}{|c|c|c|c|c|c|c|c|c|c|c|c|c|c|}
\hline \multirow[b]{2}{*}{ Variables } & \multirow[b]{2}{*}{ Contents } & \multicolumn{5}{|c|}{ Frequency } & \multicolumn{5}{|c|}{ Percentage } & \multirow[b]{2}{*}{$t / \mathrm{F}$} & \multirow[b]{2}{*}{$\begin{array}{c}p / \\
\text { Post-ho }\end{array}$} \\
\hline & & $\begin{array}{c}\text { Lack of } \\
\text { safety } \\
\text { education }\end{array}$ & $\begin{array}{c}\text { Lack of } \\
\text { safety } \\
\text { rules }\end{array}$ & $\begin{array}{c}\text { Lack of } \\
\text { professional }\end{array}$ & $\begin{array}{l}\text { Equipment } \\
1 \quad \text { aging }\end{array}$ & $\begin{array}{c}\text { Lack of } \\
\text { safety } \\
\text { awareness }\end{array}$ & $\begin{array}{l}\text { Lack of } \\
\text { safety } \\
\text { education }\end{array}$ & $\begin{array}{c}\text { Lack of } \\
\text { safety } \\
\text { rules }\end{array}$ & $\begin{array}{c}\text { Lack of } \\
\text { professional }\end{array}$ & $\begin{array}{l}\text { Equipment } \\
1 \quad \text { aging }\end{array}$ & $\begin{array}{c}\text { Lack of } \\
\text { safety } \\
\text { awareness }\end{array}$ & & \\
\hline \multirow{2}{*}{ Sex } & $\mathrm{M}$ & 128 & 177 & 140 & 428 & 80 & 13.3 & 18.4 & 14.5 & 44.4 & 8.3 & & \multirow{2}{*}{.134} \\
\hline & $\mathrm{F}$ & 165 & 172 & 133 & 430 & 84 & 16.7 & 17.4 & 13.5 & 43.6 & 8.5 & & \\
\hline \multirow{4}{*}{ Grade } & $1 \mathrm{st}$ & 103 & 108 & 86 & 243 & 34 & 17.8 & 18.7 & 14.9 & 42.0 & 5.9 & & \multirow{4}{*}{$\begin{array}{c}.036^{*} \\
{[1],} \\
{[2,3,4]}\end{array}$} \\
\hline & 2nd & 74 & 93 & 66 & 247 & 46 & 14.0 & 17.6 & 12.5 & 46.8 & 8.7 & & \\
\hline & 3 rd & 63 & 79 & 70 & 185 & 50 & 14.0 & 17.6 & 15.6 & 41.1 & 11.1 & & \\
\hline & 4th & 53 & 69 & 51 & 183 & 34 & 13.5 & 17.6 & 13.0 & 46.6 & 8.7 & & \\
\hline \multirow{2}{*}{ Major } & PE & 179 & 212 & 171 & 542 & 104 & 14.7 & 17.4 & 14.0 & 44.5 & 8.5 & \multirow{2}{*}{-1.069} & \multirow{2}{*}{.285} \\
\hline & Non-PE & 114 & 137 & 102 & 316 & 60 & 15.6 & 18.7 & 13.9 & 43.2 & 8.2 & & \\
\hline \multirow{2}{*}{$\begin{array}{l}\text { Accident } \\
\text { experience }\end{array}$} & Yes & 143 & 166 & 142 & 506 & 98 & 13.4 & 15.6 & 13.3 & 47.5 & 9.2 & \multirow{2}{*}{4.505} & \multirow{2}{*}{$.000^{* *}$} \\
\hline & No & 150 & 183 & 131 & 352 & 66 & 17.0 & 20.7 & 14.8 & 39.8 & 7.5 & & \\
\hline
\end{tabular}

$* p<.05, * * p<.01$, post-hoc [ ]

Table 14. Government-level alternatives

\begin{tabular}{|c|c|c|c|c|c|c|c|c|c|c|c|c|c|}
\hline \multirow{2}{*}{ Variables } & \multirow{2}{*}{ Contents } & \multicolumn{5}{|c|}{ Frequency } & \multicolumn{5}{|c|}{ Percentage } & \multirow{2}{*}{$t / \mathrm{F}$} & \multirow{2}{*}{$\begin{array}{c}p / \\
\text { Post- } \\
\text { hoc }\end{array}$} \\
\hline & & \multicolumn{2}{|c|}{ Promotion Education } & \multirow{2}{*}{$\begin{array}{l}\text { Law } \\
195\end{array}$} & \multicolumn{2}{|c|}{ Supervision Professiona } & 1 Promotion & Education & \multirow{2}{*}{$\begin{array}{l}\text { Law } \\
20.2\end{array}$} & \multicolumn{2}{|c|}{ Supervision Professional } & & \\
\hline \multirow{2}{*}{ Sex } & $\mathrm{M}$ & 154 & 276 & & 201 & 133 & 16.0 & 28.7 & & 20.9 & 13.8 & \multirow{2}{*}{4.973} & \multirow{2}{*}{$.000 * *$} \\
\hline & $\mathrm{F}$ & 95 & 278 & 212 & 314 & 88 & 9.5 & 28.2 & 21.5 & 31.8 & 8.9 & & \\
\hline \multirow{4}{*}{ Grade } & $1 \mathrm{st}$ & 74 & 157 & 126 & 157 & 62 & 12.8 & 27.1 & 21.8 & 27.1 & 10.7 & \multirow{4}{*}{.791} & \multirow{4}{*}{.499} \\
\hline & $2 \mathrm{nd}$ & 68 & 158 & 125 & 130 & 47 & 12.9 & 29.9 & 23.7 & 24.6 & 8.9 & & \\
\hline & $3 r d$ & 55 & 134 & 86 & 120 & 54 & 12.2 & 29.8 & 19.1 & 26.7 & 12.0 & & \\
\hline & 4th & 52 & 105 & 70 & 108 & 58 & 13.2 & 26.7 & 17.8 & 27.5 & 14.8 & & \\
\hline \multirow{2}{*}{ Major } & $\mathrm{PE}$ & 169 & 377 & 244 & 266 & 158 & 13.9 & 31.0 & 20.0 & 21.8 & 13.0 & \multirow{2}{*}{5.152} & \multirow{2}{*}{$.000 * *$} \\
\hline & N0n-PE & 80 & 177 & 163 & 249 & 63 & 10.9 & 24.2 & 22.3 & 34.0 & 8.6 & & \\
\hline \multirow{2}{*}{$\begin{array}{c}\text { Accident } \\
\text { experience }\end{array}$} & Yes & 128 & 301 & 218 & 265 & 150 & 12.0 & 28.2 & 20.5 & 24.9 & 14.1 & \multirow{2}{*}{-.284} & \multirow{2}{*}{.776} \\
\hline & No & 121 & 253 & 189 & 250 & 71 & 13.7 & 28.6 & 21.4 & 28.3 & 8.0 & & \\
\hline
\end{tabular}

$* p<.05, * * p<.01$ 
스포츠 안전사고를 예방하기 위한 정부 차원의 대안이 무엇이라 생 각하느냐는 질문에 남성과 여성의 차이가 있었다 $(t=4.973, p=.000)$. 남성은 안전 관련 교육 활성화를 최우선으로 생각하고 있었고, 여성은 사업장의 관리 및 감독으로 생각하고 있었다. 학년 간에는 차이가 없 었다( $F=.791, p=.499)$. 안전 관련 교육 활성화를 스포츠 안전사고 예 방을 위한 정부 차원의 대안이 필요하다고 응답하였다.

전공 별로 차이가 있었으며 $(t=5.152, p=.000)$, 체육계열 학생은 안 전 관련 교육 활성화를 최우선 정부의 대안으로 뽑은 반면, 비 체육계 열 학생은 사업장의 관리 및 감독 강화를 가장 최우선으로 정부가 이 루어야 할 대안으로 보았다.

사고의 경험 유무에 따라서는 집단 간 차이가 없었다 $(t=.-284$, $p=$.776) (Table 14).

\section{논의}

본 연구는 대학생의 스포츠 안전의식을 조사하기 위하여 전국의 대학 생을 모집단으로 하여 대학을 선정한 후 선정된 대학의 학생을 대상으 로 설문조사를 실시하였다. 설문조사를 통하여 안전교육, 스포츠 안전 의식, 스포츠 안전관리 등에 대한 조사를 실시하였다

성인기 이전의 스포츠 참여경험은 평생 스포츠 활동을 하는 밑거 름이 될 수 있어 개인에게 있어서는 대학생의 스포츠 활동 참여경험 이 건강하고 행복한 삶을 영위하는데 중요한 역할을 한다. 특히 대학 생의 자발적인 스포츠 활동 참여는 자신의 건강 유지 및 증진 뿐 아니 라 풍요로운 학교생활과 사회생활을 영위할 수 있도록 한다. 그러나 스포츠 활동이 증가할수록 스포츠로 인한 상해도 증가하여 지속적으 로 스포츠 활동을 하지 못하고 중간에 그만두는 현상이 나타나고 있다 (Ministry of Culture, Sports and Tourism, 2020). 연구결과 분석을 통해 검증된 내용을 중심으로 변인 간의 관계를 종합적으로 논의하고 자 한다. 스포츠 안전사고 없이 스포츠를 즐기기 위해서는 스포츠 안 전교육이 중요하다고 할 수 있는데(Shin, 2020), 본 연구결과 스포츠 안전교육을 받은 사람은 남성이 여성보다 많았고, 체육계열 학생이 비 체육계열 학생보다 안전교육을 많이 받은 것으로 조사되었다. 건강을 유지하고, 삶의 질을 향상 시키기 위해 대학 시절 스포츠 활동은 평생 생활체육의 기본이 되고 있는 점을 고려할 때(kim \& Jeong, 2021), 비 체육계열 학생들의 안전교육 강화에 더욱 노력해야 할 것으로 사 료된다. 안전교육을 통한 안전의식의 습관화가 중요하다(Kim et al., 2019). 본 연구 결과에서 스포츠 안전교육을 받은 적이 없는 사람임 에도 불구하고, 기회가 주어줘도 안전교육을 받지 않겠다는 여학생이 $41.4 \%$ 나 되었다. 특히 스포츠 안전교육을 받지 않은 학생들 중 비 체 육계열의 학생은 스포츠 안전교육의 기회가 주어진다 해도 받지 않겠 다는 사람이 많아 교과목을 통한 스포츠안전 교육이 더욱 절실히 요구 된다. 안전의식은 안전교육을 받을수록 안전의식이 높아진다는 결과 가 있으므로(Yoo, 2015), 대학에서 교양 교육과정 중 스포츠 안전교 육이 확대되어야 할 것이다. 특히 비 체육계열 학생은 체육계열 학생 에 비해 스포츠 현장에서 스포츠 안전 교육을 받은 비율이 낮아 대학 의 정규과정 속에 스포츠 안전 교육과 함께 응급처치 교육이 이루어져 야 할 것이다. 안전의식은 안전에 대한 분위기가 생성되어 있으면 안 전에 대한 행동을 적극적으로 행하게 되는데(Shin \& Kim, 2021), 대 학생의 안전교육을 통한 안전의식 고취가 필요한 실정이다. 대학생들 의 안전교육 실태에 관한 선행연구가 미비하여 직접적으로 비교하여
논의하기 어려운 점이 있으나 스포츠 안전의식 확산을 위한 스포츠 안 전교육확대는 필요하다. 학교에서 스포츠 안전교육이 이루어지지 못 하더라도, 스포츠 현장에서 안전교육 강화가 필요하다. 또한, 본 연구 결과로는 대학생들이 스포츠 현장에 안전담당자가 없거나 안전담당자 배치에 대해 잘 모르고 있었다. 대학과 스포츠 현장에서 스포츠 안전 교육이 철저하게 이루어지면 스포츠 안전문화가 형성되고 안전의식도 고취될 것이다.

스포츠 안전의식도 다른 재난 및 안전에 대한 의식과 마찬가지로 스 포츠 안전의식에 필요한 교육, 훈련, 캠페인 및 홍보, 안전행동요령 지 침 등을 보급하여 안전에 대한 가치와 인식을 높여야 한다(Shin et al., 2021), 이를 통하여 스포츠 사고로부터 안전하게 스포츠를 즐길 수 있 는 문화를 만들 수 있다. 본 연구가 대학생의 스포츠 안전의식을 조사 했지만, 스포츠 안전의식은 국민 개개인이 가져야 할 주체이며, 공공 기관은 각종 교육, 홍보, 스포츠 안전에 대한 가치부여 등의 노력을 통 해 스포츠 안전의식이 증진될 수 있도록 노력하여야 한다. 안전의식은 개인이나 공공기관의 안전의식을 높이기 위한 활동으로 이어질 수 있 고, 이것은 우리사회에 스포츠 안전문화로 정착될 수 있다.

대학생의 스포츠 안전의식정도를 알아보기 위해 스포츠 안전에 대 한 생각을 조사하였다. 본 연구결과는 많은 학생이 스포츠는 안전하지 않다고 인지하고 있었다. 스포츠가 안전하지 않다고 생각하는 이유는 스포츠 현장의 시설이나 장비가 관리되지 않거나 노후 된 것이 스포츠 가 안전하지 않다고 인식하고 있는 이유였으며, 스포츠 안전사고 관련 뉴스 및 기사 그리고 주변에서 스포츠는 안전하지 않다고 하는 의견들 로 많은 대학생들은 스포츠가 안전하지 않다고 인식하고 있었다. 우리 나라에 체육시설의 설치이용에 관한 법률은 제정되어 있지만 법적으 로 스포츠 시설의 안전을 위하여 주기적으로 시설이나 장비를 점검해 야 하는 법이 없어 스포츠 현장에서 노후화된 스포츠 시설이나 장비가 많은 사고의 원인이 된다. 스포츠가 안전하다고 느낄 때 스포츠를 더 욱 즐길 수 있고, 학생들의 안전의식 정도가 높을수록 안전생활 실천 정도가 높은 것으로 보고되고 있어(Yoon et al., 2014) 대학생의 스포 츠 안전의식을 높이기 위해 스포츠 현장의 시설관리가 우선적으로 이 루어져야 하며, 안전사고를 줄이는 것이 선행되어야 할 것이다.

스포츠 현장의 안전시설에 관하여 '체육시설의 설치이용에 관한 법 률'이나 '사격 및 사격장 단속법' 등과 같이 스포츠에 관련된 개별법상 안전 관련 조항이 명시되어 있을 뿐 스포츠 안전관리에 관한 법률이 제정되어 있지 않다(Shon, 2011).

안전사고 예방을 위한 사전 관리나 사고 발생 시 대응조치에 대해 대학생들은 '보통이다', '약간 그렇다'라고 응답한 사람이 대부분이었 다. 안전관리를 위해 사고예방이나 대응조치에 대하여 명확한 관리 및 대응 매뉴얼이 필요하다. 선행연구에서는 과거 사고 및 재난 경험이 있는 학생들이 경험이 없는 학생보다 안전의식이 낮았다는 보고가 있 었으나(Kim, 2015), 대학생의 안전의식에 관한 연구가 부족하여 명확 히 비교는 어려웠고, 본 연구결과는 사고 경험이 없는 사람과 사고가 있는 사람 간 차이가 없었다.

안전사고의 주된 원인을 대학생들은 여성과 남성, 사고 경험의 유 무와 상관없이 시설 및 장비의 노후도라고 응답하였다. 스포츠 안전사 고를 예방하여 스포츠 사고 관련 뉴스를 줄이고 주변 사람들이 스포츠 를 안전한 문화라 여길 때 스포츠 안전의식은 문화로 자리 잡을 수 있 을 것이다. 그 외의 안전사고가 발생하는 주된 이유로 안전교육의 미 비, 스포츠 사업장의 안전수칙 이행 부족, 전문 운영인력 부족, 이용자 의 안전의식 부족 및 부주의를 들었다. 스포츠 활동 시 준비운동 실시, 
시설물 안전여부 확인, 안전시설 확인, 위험지역 확인, 보호장구 착 용 등 실천적 습관이 이루어질 때 안전문화가 정착될 수 있다 $(\mathrm{Kim}$, et al., 2019).

스포츠 안전사고를 예방하기 위한 정부차원의 대안으로 가장 절실 히 필요한 것은 사업장의 관리 및 감독 강화와 안전관련 교육의 활성 화 다. 그 외에 안전에 대한 지속적인 홍보와 스포츠 관련 법규 제정 및 정비, 사업장의 전문 인력 양성이 필요하다. 스포츠 안전의식이 확 산되고 스포츠 안전의식에 대한 조사가 선행된 연구가 부족하여 본 연 구와 비교하여 논의하기 어려운 점이 많아 추후 연구에서는 좀 더 많 은 스포츠 안전의식에 관한 조사연구가 이루어져 많은 후속적인 연구 가 진행되기를 기대한다.

\section{결론 및 제언}

본 연구는 전국의 대학생을 대상으로 설문을 통해 스포츠 안전의식을 조사하였다. 그 결과 다음과 같은 결론을 얻었다.

첫째, 안전하게 스포츠를 즐기기 위해서는 무엇보다도 스포츠 안전 교육이 중요하다. 우선적으로 대학의 교과과정 중 스포츠 안전교육이 확대되어 대학에서 안전교육이 철저하게 이루어지고, 이에 더하여 스 포츠 현장에서도 안전교육 강화가 필요하다.

둘째, 스포츠 현장의 시설이나 장비의 관리미흡과 노후화가 스포츠 사고의 원인이 된다. 노후 된 장비 교체와 관리 철저가 필요하다.

셋째, 스포츠 안전사고 예방을 위한 정부차원의 대안으로는 사업장 의 관리 및 감독 강화가 필요하다.

넷째, 그 외에 안전에 대한 홍보와 스포츠 관련 법 제정 및 정비, 사 업장의 전문 인력 양성이 필요하다.

스포츠를 제대로 즐기기 위해서는 무엇보다도 안전한 스포츠 활동 이 최우선시 되어야 한다. 스포츠 안전사고를 예방하기 위해서는 스포 츠를 즐기는 사람 스스로가 안전의식을 가지고 사고 예방에 힘써야 한 다. 스포츠 안전의식이 정착이 되어 안전한 스포츠 안전문화를 형성하 는 일이 중요하다. 본 연구 결과를 토대로 살펴 본 결론 이외에도 스포 츠 안전문화 정착을 위해서는 스포츠 활동을 할 수 있는 안전한 시설 이 확보되어야 한다. 물론 체육시설 설치이용에 관한 법률이 제정되어 있지만 조금 더 운영적인 측면에서 안전을 저해할 수 있는 요소들을 제거할 수 있는 안전관리 규정과 이에 대한 행정규제 등 법령에 의한 제도적인 장치의 마련이 필요하다.

안전한 스포츠 문화를 정착시키기 위해 대학생의 스포츠 안전문화 의식을 고취시켜야 한다. 스포츠 안전의식에 대한 연구가 미흡하여 본 연구와 선행연구의 비교 분석이 어려웠던 만큼 추후 좀 더 많은 스포 츠 안전의식에 관한 연구가 이루어져 스포츠 안전의식에 대한 활발한 논의가 이루어지길 필요가 있다. 스포츠 안전의식은 대학생에게만 필 요한 것이 아니고, 전 국민에게 확산되어 모든 국민들이 안전하게 스 포츠를 즐길 수 있는 문화가 정착되길 기대한다. 


\section{참고문헌}

Chung, J. B., \& Yoon, G. (2014). Safety innovation master plan. Economic Humanities and Social Research Society, 3, 7-11.

Chung, S. I., \& Oh, J. Y. (2016). A study on situation of safety education in universities and university students awareness of coping methods for safety accidents. Journal of Korea Contents Association, 16(12), 518-529.

Hong, D. S., Lee, J. H., \& Kim, E. J. (2018). A comparative study on the survey and recognition of life sports safety accidents in Korea and Germany. The Korea Journal of Sports Science, 27(4), 891900 .

Kim, M. O., Yeo, K. A., \& Kwon. Y. T. (2019). A study on the safety consciousnsess of sports participants. Jounal of Korean Society of Sport Policy, 17(1), 149-158.

Kim, S. Y. (2015). Safety Awareness and Safety Practice Behavior of College Students. Journal of Digital Convergence.13(2), 279289.

Kim, Y. R., \& Jeong, Y. D. (2021). Examining the relationships among service quality of general physical education, exercise commitment, and exercise adherence intention for life in female university. Journal of Sport and Leisure Studies, 86, 177-189.

Lee, H. B. (2015). Measures to Spread the Safety Culture Movement and Raise Safety Awareness. Dejeon Development Institute.

Lee, H. T. (2010). The effect on safety life practicing behavior by safety consciousness and safety awareness. Ph.D. Dissertation, Daegu Hanny University.

Lee, J. H., Won, Y. S., \& Park, H. K. (2019). The Relative Risk Ratio of Recognition of Responses for the Sports Accidents by Experience in Sports Activities, Participating in Sports Safety Education, and Buying Insurance(Mutual-Aid). Korean Journal of Sociology of Sport, 32(3), 89-101.

Ministry of Culture, Sports and Tourism. (2020). National Life Sports Survey.

Park, S. J. (2009). A Inquiry of happiness pursuit through sports activity. Korean Journal of Psychological and Social Issues, 15(1), 241-250.

Shin, O. S., \& Kim Y. J. (2021). A study on the differences between safety awareness and health behavior of participants in leisure physical activities. The Korean Journal of Sport, 19(1), 313-320.

Shin, Y. C. (2020). The Impact of Virtual Reality Sport Safety Education on Elementary School Students' Safety Awareness and Safety Behavior. Master Dissertation, Korea National Sport University.

Shin, J. D., Lee, D. K., Won, J. Y., \& Park, S. Y. (2021). Safety Consciousness Concept and Measuring Scope. Journal of Korean Society of Hazard Mitigation, 21(1), 93-100.

Shon, S. J. (2011). A study on the legislation for the sports safety in Korea. The Korean Association of Sports and entertainment law, 14(3), 121-143.

Yoo, S. J.(2015). Analysis of nutritional factors of safety awareness:
Focusing on life safety. The Korean Association for Policy Development, 15(1), 37-68.

Yoon, Y. M., Sung, K. S., \& Kim, E. J. (2014). Safety consciousness and safety practicing behavior and perception about safety management service system of university campus among university students. The Korean Society of Living Environmental System, 21(6), 1033-1042. 


\section{대학생 스포츠 안전의식 조사 연구}

\section{남윤신}

덕성여자대학교 교수

[목적] 본 연구는 대학생 스포츠 안전의식을 조사하고 살펴보는데 있었다.

[방법] 전국 남녀 대학생을 대상으로 단순무선표집법을 이용하여 연구대상 대학을 선정하고, 난수표를 이용하여 9개 권역 으로 나누어 설문조사를 실시하였다. 설문대상자는 1950 명이었다.

[결과] 첫째, 남성이 여성에 비해 안전교육을 받은 경험이 많았고( $\mathrm{P}=.000)$, 스포츠 안전교육은 주로 학교 현장에서 이루어 졌다. 스포츠 현장의 안전담당자를 모르고 있는 경우가 많았다. 둘째, 스포츠가 안전하지 않다고 생각하고 있다. 스포츠 가 안전하지 않다고 생각하는 이유는 시설 및 장비가 관리되지 않고 노후하기 때문인 것으로 나타났다. 셋째, 스포츠 안 전관리는 대체로 보통이라고 인식하고 있었다. 스포츠 사업장의 시설 및 장비의 노후화가 안전사고 발생의 주요 요인으 로 인식하고 있었다. 스포츠 안전사고를 줄이기 위해서 정부차원의 대안으로는 안전교육활성화가 가장 필요하다.

[결론] 본 연구의 결과는 안전한 스포츠 문화를 정착시키기 위한 대학생의 안전문화 의식을 높이는데 기초자료로 사용될 것이다.

주요어

대학생, 스포츠, 안전의식, 조사 